\title{
The SIALON Project: Report on HIV Prevalence and Risk Behaviour Among MSM in Six European Cities
}

\author{
Massimo Mirandola et al.* \\ Azienda Ospedaliera Universitaria Integrata Verona (The Hospital Trust of Verona), \\ Coordinamento Regionale per il Management e la Progettazione Europea (Regional \\ Coordination Centre for European Project Management), Veneto Region, Verona,
}

Italy

\section{Introduction}

The following chapter describes the process and results of a survey conducted in six cities in Southern and Eastern Europe to obtain data on (i) the prevalence of HIV and Syphilis among Men who have Sex with Men (MSM), (ii) sexual behaviour risk patterns of MSM and (iii) the determinants of access to Voluntary Counselling and Testing (VCT) by MSM.

The chapter describes how the survey was undertaken against a backdrop of evidence indicating a rising incidence of HIV infection in Europe and in the context of a gap in information on HIV incidence and prevalence amongst the MSM community which has been identified as an at risk population for HIV infection.

In this context, the methodology used for obtaining reliable information and data, represents a key factor in the process. The Time-Location Sampling (TLS) method has proven to be an effective means for gathering both behavioural and biological data in hidden or hard to reach populations, such as MSM.

The chapter provides a description of the implementation of TLS for epidemiological purposes and a summary of the main results of the survey which reveal (i) a high unawareness of HIV positive serostatus, (ii) a higher risk among younger people of obtaining the HIV infection due to their risk behaviour (e.g. unprotected anal intercourse)

\footnotetext{
* Jean-Pierre Foschia ${ }^{2}$, Michele Breveglieri², Martina Furegato², Enrica Castellani2, Ruth Joanna Davis¹, Lorenzo Gios ${ }^{1}$, Dunia Ramarli ${ }^{3}$ and Paola Coato ${ }^{4}$

${ }^{1}$ Azienda Ospedaliera Universitaria Integrata Verona (The Hospital Trust of Verona), Coordinamento Regionale per il Management e la Progettazione Europea (Regional Coordination Centre for European Project Management), Veneto Region, Verona, Italy

${ }^{2}$ ULSS20, Veneto Region, Verona, Italy

${ }^{3}$ UO immunologia (Department of Pathology, Immunology), Azienda Ospedaliera Universitaria Integrata Verona (The Hospital Trust of Verona), Verona, Italy

${ }^{4} \mathrm{UO}$ immunologia (Department of Pathology, Microbiology), Azienda Ospedaliera Universitaria Integrata

Verona (The Hospital Trust of Verona), Verona, Italy
} 
and a more limited access to HIV screening services and prevention programmes, (iii) the correlation between HIV infection and STIs and Syphilis and (iv) the association between HIV risk and alcohol and drug use.

This chapter also discusses the use of UNGASS indicators and the Second Generation Surveillance System (SGSS) approach in the survey and in general as key features to be considered as part of a comprehensive surveillance system.

Finally, a number of conclusions are drawn with regard to the need for repeated epidemiological studies focusing on hard to reach populations as well as to the need for targeted health promotion and prevention campaigns.

\section{Background}

HIV infection remains a relevant issue in Europe in the field of public health. Moreover, scientific literature suggests an increasing HIV transmission in several European countries. MSM represent one of the most at risk populations for acquiring HIV. In 2009, 9,023 newly diagnosed HIV infections were reported among this population in Europe, which accounts for $35 \%$ of all HIV diagnoses in that year (European Centre for Disease Prevention and Control ECDC/World Health Organisation WHO - Regional Office for Europe, 2010; Likatavicius et al., 2008). Moreover, in this specific population, a high level of risk behaviours associated with an increasing incidence of other Sexually Transmitted Infections (STI) clearly show the need for specific and targeted prevention campaigns (Dodds et al., 2005; Van de Laar et al., 2009).

Due to a lack of risk perception and also to perceived social stigma, MSM tend to refer a low level of VCT and active health seeking behaviours (MacKellar et al., 2005). In addition, social and cultural obstacles to testing can be perceived by MSM also in health facilities. From a methodological point of view, since the introduction of Highly Active Anti-Retroviral Therapy (HAART), AIDS has become less indicative of the underlying trends in HIV infection, for this population in particular. Data based on the clinical records, at the same time, seems to not realistically reflect the HIV trends for two reasons. On the one hand, clinical records often do not include information regarding hard-to-reach MSM, who are less likely to ask for VCT and regular testing. On the other hand, a low level of knowledge about the real serostatus is reported among MSM (Williamson \& Hart, 2007; Mirandola et al., 2009). Therefore, specific surveillance and outreach research targeting MSM who cannot attend the clinical facilities, is strongly required in order to obtain a more realistic estimation of the HIV epidemic.

In this context, a need for reliable and comparable data across different countries is also a key issue in monitoring the spread of HIV and in providing meaningful prevention. Unfortunately, data are often collected across a number of countries or in the same country using different sampling methods, or different testing methods, or different testing algorithms. In addition, questionnaire items used in various studies are often based on different assumptions and they can vary greatly in terms of time frame of the questions (last 12 or 3 months, last intercourse), definition of risk sexual practice, etc. Finally, specific HIV surveys focusing on MSM are rarely repeated on a regular basis. For that reason, a lack of reliable data and trends on HIV epidemic is available for this at risk population. 
In this framework, a specific Declaration of Commitment on HIV/AIDS and a Political Declaration on HIV/AIDS were proposed and adopted by the UN General Assembly in 2001. In these documents, a specific set of epidemiological and surveillance activities are suggested, as well as the adoption of the so-called UNGASS indicators. UNGASS indicators are a set of measures to be used among different countries in order to effectively monitor the HIV epidemic (Joint United Nations Programme on HIV/AIDS UNAIDS \& World Health Organization WHO, 2009). The Declaration provides a comprehensive framework to achieve the Millennium Development Goal in order to reverse the HIV epidemic by 2015.

In addition, specific indications for developing and implementing a more effective surveillance system are provided in UNAIDS and WHO publications (UNAIDS \& WHO, 2002, 2005). These documents suggest the adoption of the so-called Second Generation Surveillance System (SGSS), which foresees a set of detailed managerial and epidemiological procedures, as well as standardized processes and actions for managing surveillance studies. The SGSS foresees the implementation of surveys repeated on a regular basis according to different indicators, which require the collection of both behavioural and biological data. The SGSS provides a meaningful tool for developing prevention initiatives according to reliable data on HIV epidemics and behavioural patterns, which represent the major challenge for the coming years.

The "Capacity building in HIV/Syphilis prevalence estimation using non-invasive methods among MSM in Southern and Eastern Europe" - SIALON project was developed and implemented according to the main procedures and processes foreseen in the UNGASS declaration and in the SGSS approach. The SIALON project was funded in the framework of the 2003-2008 Public Health Programme (Work Plan 2007) and implemented by a team of European Public Institutions under the leadership of the Veneto Region in close collaboration with local partners ranging from Universities, teaching hospitals, epidemiological centres and Gay NGOs. In particular, the SIALON study was carried out in six cities of Southern and Eastern European countries: Barcelona (Spain), Bratislava (Slovakia), Bucharest (Romania), Ljubljana (Slovenia), Prague (Czech Republic), Verona (Italy).

\section{Methods}

\subsection{Study design}

The study conducted during the SIALON project was a cross-sectional study targeting MSM who have had sex with another man during the last 12 months. The data collection was conducted according to the Time-Location (or Time-Space) Sampling (TLS) procedure. This method was used to recruit men visiting the selected gay settings in each participating city, allowing to construe a representative sample with known properties. The cross-sectional study was conducted using a self-administered pen-and-paper questionnaire and an oral fluid collector to gather both behavioural and biological data for each participant.

The study design was planned and implemented in line with the Second Generation Surveillance System (SGSS) criteria (UNAIDS \& WHO, 2002, 2005) and the United Nations General Assembly Special Session (UNGASS) Indicators (UNAIDS \& WHO, 2009).

\subsubsection{Study population}

According to data and the results of some seroprevalence studies, levels of HIV prevalence are between 10 and 20\% among MSM. As mentioned in section 2, this specific 
sub-population continues to be at high risk of HIV infection, especially in Europe, and according to the available data a hidden HIV epidemic seems currently underway (ECDC, 2010; Likatavicius et al., 2008). Because of a high level of risk sexual practices, MSM become a key population for HIV surveillance. In addition, especially because of stigma, a low level of VCT is reported, particularly among hard-to-reach MSM who do not attend health services regularly. Moreover, since the introduction of HAART, AIDS has become less indicative of the underlying trends in HIV infection, for this population in particular. For these reasons, field research and surveillance activities targeting this specific population seem to be essential in monitoring the HIV epidemic and in developing preventive action in Europe.

\subsubsection{Sampling}

The sample size estimation for a prevalence study was calculated on the basis of previous prevalence estimation studies, where available (Folch et al., 2005). According to this calculation, a total of 2,800 persons (400 per city) were planned to be included in the data collection process.

Time-Location (or Time-Space) Sampling (TLS) was used to recruit representative samples of men visiting the gay scene in each city. This specific approach was used in previous studies (Williamson \& Hart, 2007; Stueve et al., 2001; MacKellar et al., 2007; Gallagher et al., 2007; Muhib et al., 2001), and has proven to be a good and reliable method for gathering both behavioural and biological data in hidden or hard to reach populations. According to the TLS method, spaces (locations) are venues attended by the target population, in this case MSM, while times refer to specific days and time periods when the target population attends each identified space or setting. This sampling approach allows to construe a sample with known properties, enabling statistical inferences to be made to the larger population of venue visitors (ideally, all MSM attending the gay scene in each city).

In order to identify timing and settings, a specific formative research was conducted in each city. The first step in the formative research was the identification and selection of all gay venues in the given city. Bars, discos, saunas, cruising venues, sex-shops, sex-clubs were therefore identified. All venues were mapped and visited when information was not sufficient. This process allowed to identify the potential TLS units (the attendance time frame, opening days and hours) and to create a specific data collection calendar. The spaces and their associated days were divided into standardised time segments (four-hour periods). MSM were then enrolled over the entire TLS unit time period. During the data collection sessions, information regarding the number of refusals per unit was registered. In order to include all possible time and location units that did not occur frequently but that may attract members of the target population, also settings or special gay events were identified and mapped, creating a "special events" category. A list of TLS units was created according to this sampling approach, where the TLS units were the "primary sampling units" (PSU). In addition, in creating the final list of TLS units, safety and feasibility of data collection in different settings and at different times (especially in cruising venues) was taken into account. At this stage, the PSU were randomly selected from complete list of eligible TLS list in each participating city. 


\subsection{Data collection and analysis}

\subsubsection{Questionnaire}

The SIALON questionnaire was specifically designed according to the international literature and according both to the study design and the data collection procedures. The self-administered pen-and-paper questionnaire was developed to obtain information on a range of different aspects and taking into account both UNGASS and ECDC indicators. The first part refers to background data. The second part lists items on sexual practices, riskreducing strategies, condom use, STI history and self-reported/perceived serostatus.

Moreover, questions regarding number of both steady and casual partners were foreseen, as well as frequency and type of sexual practices in both cases. In construing the different questions, specific attention was paid to the social/cultural/environmental and contextual variables, as well as to access and barriers to VCT.

From a structural point of view, the questionnaire contained items referring to different time-spans: last 12 months, last 6 months, and last time (last sexual intercourse). This structure allowed to include all items needed for the construction of the UNGASS and ECDC indicators.

In terms of the UNGASS and ECDC indicators themselves, according to the WHO-UNAIDS documents, questions referring to UNGASS 8 (testing), 9 (prevention campaigns), 19 (condom use) and 23 (HIV prevalence) were included.

Finally, specific attention was paid to the time span required to fulfill the questionnaire: a maximum of 20 minutes was required for completing the questionnaire. For this purpose, specific piloting was conducted.

\subsubsection{Enrolment}

With regard to the enrolment of subjects, a specific easy-to-use and practical manual was provided to all data collectors, in order to standardise all procedures and to guarantee the safety and reliability of data collected. Following the data collection calendar created through the TLS method, trained field workers from gay associations attended the different gay venues in specific time-location units. The self-administered pen-and-paper questionnaires were distributed, as well as the Oracol devices for oral fluid collection (Malvern Medical Developments, Worcester, UK). Both self-completed questionnaires (behavioural data) and oral fluid samples (biological data) were collected for each subject. A unique barcode for each subject was used to link behavioural and biological information.

Finally, regarding the enrolment period, this varied between the different participating cities, according to the different situations and calendars (from 2 months to 9 months), starting in November 2008 and ending in October 2009.

\subsubsection{Statistical analysis}

Mean, median, standard deviation, quartiles and inter-quartiles were calculated and proportions with $95 \%$ confidence intervals $(\mathrm{CI})$ were adopted for all variables and indicators. With regard to the UNGASS indicators calculation, specific reference to the UNGASS-WHO publications was made. Finally, STATA 11 survey commands suite was used. 


\subsection{Laboratory testing}

\subsubsection{Oral fluid sampling and testing}

To collect oral fluids, Oracol oral fluid collection kits (Malvern Medical Developments, Worcester, UK) were used. The main advantages for replacing serum with oral fluid were easy access and non-invasive collection. After collection, oral fluid samples were kept refrigerated and sent to the national reference laboratory for HIV/AIDS in the respective countries no more than 72 hours after collection.

\subsubsection{HIV testing}

The oral fluid samples were sent for the analysis by each national reference laboratory to the Teaching Hospital-University of Verona, Immunology Unit, Verona, Italy. EIA testing GENSCREEN HIV 1/2 version 2, BIO-RAD on oral fluid sample was performed according to the manufacturer's instructions. All positive samples were confirmed with a Western Blot test. In terms of quality control, for each oral fluid sample, a total IgG antibodies ELISA test was performed in order to assess the sample suitability for testing. Samples below 3.5 titre (cut-off) were excluded from the study as invalid (see Fig. 1: Survey testing algorithm). A validation

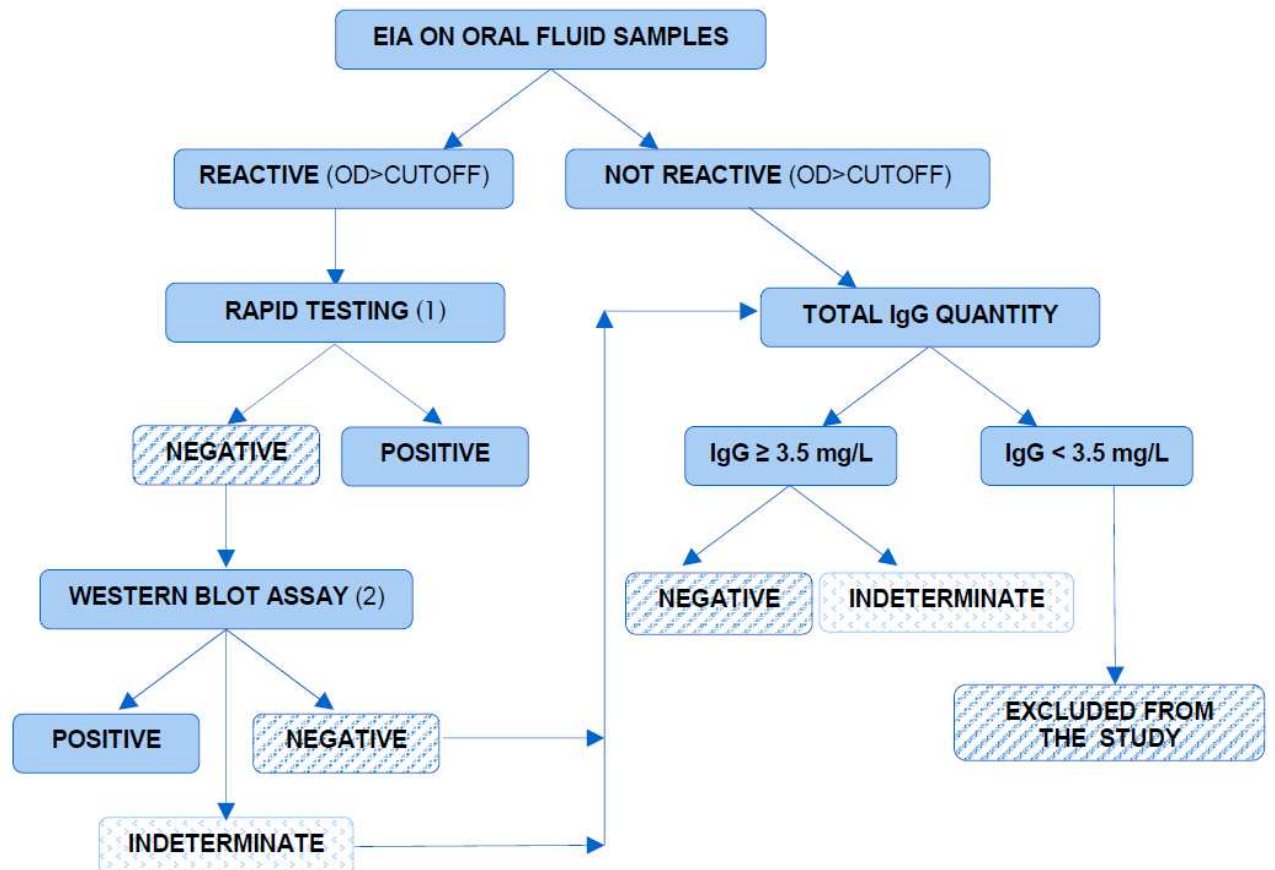

(1) Rapid Immunocromatograpy Determine HIV 1/2 ( Unipath Ltd, Bedford UK) CE marked for serum were used

(2) HIV 1/2 BLOT 2.2 ( MP Biomedical, China) CE marked for serum

Fig. 1. HIV testing algorithm on oral fluid samples 
study of Bio-Rad OF testing comparing serological testing involving $37 \mathrm{HIV}$ positive patients and 35 controls per country was carried out according to Commission decision of 7 May 2002 on common technical specifications for in vitro medical devices. EIA on oral fluid samples from 259 of the 263 HIV positive subjects were positive, giving a sensitivity of $98.5 \%$ (CI 96.299.6). All 233 controls were found negative for HIV in oral fluid and no false positives were detected (100\% specificity; CI 98.4-100). The positive and negative predictive values of the OF test according to HIV prevalence are presented in Table 1.

\begin{tabular}{|c|c|c|}
\hline Prevalence & $5 \%$ & $15 \%$ \\
\hline PPV & $100 \%$ & $100 \%$ \\
\hline NPV & $99.9 \%$ & $99.7 \%$ \\
\hline
\end{tabular}

Table 1. PPV and NPV according to prevalence

\section{Results}

\subsection{General description of the sample}

In this section, the description of the sample is provided in terms of number of MSM recruited, questionnaires and oral fluid samples collected, and characteristics of the sample.

\subsubsection{Numbers of subjects recruited}

A total of 2,592 subjects were recruited as follows: 408 MSM in Prague, 185 in Athens, 405 in Verona, 398 in Bucharest, 394 in Bratislava, 401 in Ljubljana and 401 in Barcelona. This study does not include the analysis of data from Athens as the Greek partner did not achieve the data collection.

\subsubsection{Questionnaires and oral fluid samples collected}

Table 2 shows the number of questionnaires and the number of oral fluid samples gathered during the data collection period for each country. Both the number of valid and invalid questionnaires and OF samples are given. From a general point of view, the percentage of invalid questionnaires is low, with the highest percentage in Ljubljana $(0.7 \%)$. In three cases the percentage is $0 \%$ (Athens, Bucharest and Bratislava). With regards to the OF samples, in

\begin{tabular}{|l|c|c|c|c|c|c|c|}
\hline & Prague & Athens & Verona & Bucharest & Bratislava & Ljubljana & Barcelona \\
\hline Questionnaires & 408 & 185 & 405 & 398 & 394 & 401 & 401 \\
\hline Valid & 407 & 185 & 404 & 398 & 394 & 398 & 400 \\
\hline$\%$ invalid & 0.2 & 0.0 & 0.2 & 0.0 & 0.0 & 0.7 & 0.2 \\
\hline OF samples & 418 & 178 & 400 & 398 & 396 & 399 & 399 \\
\hline Invalid & 31 & 28 & 9 & 53 & 10 & 10 & 10 \\
\hline \% invalid & 7.4 & 15.7 & 2.3 & 13.3 & 2.5 & 2.5 & 2.5 \\
\hline
\end{tabular}

Table 2. Number of questionnaires and OF samples collected and percentage of valid samples 
two cities the percentage of invalid samples is higher than $10 \%$ (Athens 15.7\%; Bucharest $13.3 \%$ ). In the other cities the percentage is low, ranging from $2.3 \%$ (Verona) to $2.5 \%$ (Ljubljana, Barcelona and Bratislava).

\subsubsection{Venue types}

The proportion of subjects recruited by venue type is shown in Fig. 2. $47.1 \%$ of the respondents were recruited in a disco $(1,128 \mathrm{MSM})$. With the exception of Verona, discos were the main location where questionnaires and oral fluid were collected ( $36.7 \%$ in Prague, $71.3 \%$ in Bratislava, $65.2 \%$ in Bucharest, $64.0 \%$ in Ljubljana). Bars represented the second location in each city, in terms of number of participants (22.6\% of the total, 540 subjects). The percentage of subjects recruited in this location ranged from $3.0 \%$ in Bratislava to $32.2 \%$ in Verona. With regard to saunas, $39.1 \%$ of the sample was recruited in this setting in Verona, $26.3 \%$ in Barcelona, $15.5 \%$ in Prague, $15.3 \%$ in Ljubljana and $13.7 \%$ in Bratislava. In Bucharest there is no sauna. Taking into account the total of the sample, the percentage of MSM recruited in a sauna was $18.4 \%$. Low percentages of participants were recruited in cruising settings. Naked sex party and sex clubs were not present in Bucharest and Ljubljana, and the percentages of MSM recruited in this type of venue ranged from $6.4 \%$ in Verona up to $15.5 \%$ in Prague.

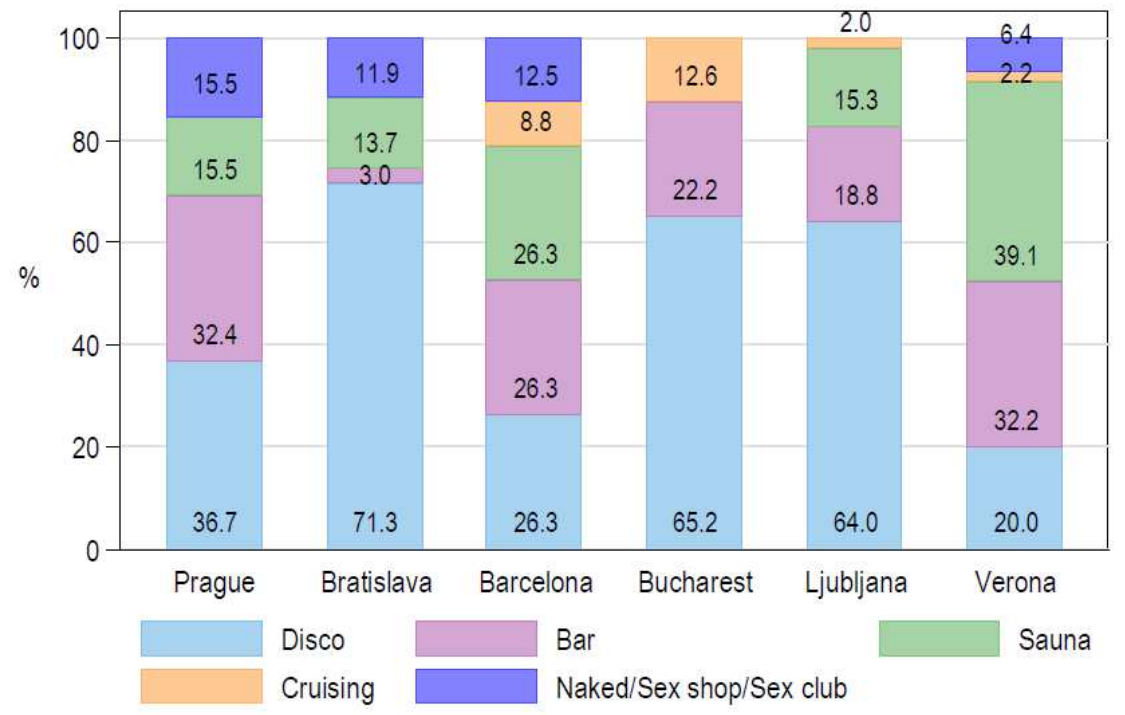

Fig. 2. Subjects recruited by venue type

\subsubsection{Age of subjects}

Median age and age distribution by city are presented in Figure 3. Respondents in Barcelona and Verona had a similar age distribution and were older (38 and 35 years respectively) than those in Eastern European cities. 


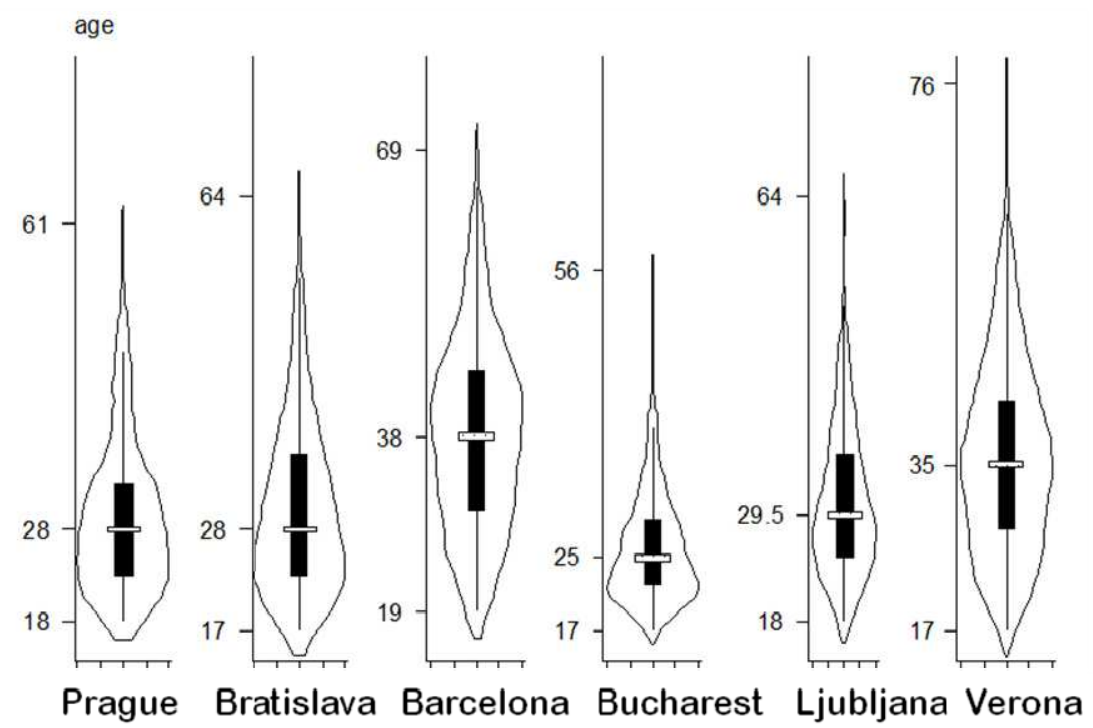

Fig. 3. Age distribution of MSM recruited by city

\subsection{UNGASS indicators}

In this section, the main data referring to the UNGASS indicators are provided. As mentioned in section 2, a specific Declaration of Commitment on HIV/AIDS and a Political Declaration on HIV/AIDS were proposed and adopted by the UN General Assembly in 2001. In these documents, a specific set of epidemiological and surveillance activities are proposed, as well as the adoption of the so-called UNGASS indicators. UNGASS indicators are a set of measures to be used among different countries in order to effectively monitor the HIV epidemic (UNAIDS \& WHO, 2009). The idea which is behind the UNGASS indicators is that all data provided by the different countries can represent a reliable picture of the status of the epidemic and on the different prevention activities implemented against the spread of $\mathrm{HIV}$ in specific and general population.

The national-level UNGASS indicators are basically divided into three categories. The first one refers to the National commitment and action, taking into account topics as policy decisions, financial plan and activities for the HIV prevention, testing and treatment, drugs and care as well. The second category refers to knowledge and behaviour in different population, while the third category refers to the national level programme impact. For all these three areas, specific guidelines and procedures on how these indicators have to be calculated are provided (for instance, they provide specific numerators and denominators to calculate the different percentages and levels of the indicators).

Despite the relevance and importance of the UNGASS Declaration and the number of countries involved in this process, it should be mentioned that to date, a number of limitations in the UNGASS reporting have emerged. For instance, in 2008 less than half of those countries that stated the indicators and procedures referring to the most-at-risk populations (MSM included) were able to provide data based on these very indicators. 
In this regard, one of the added values of the SIALON project is to provide reliable data on behaviours and HIV infection levels based on the UNGASS procedures and indicators. In some of the participating countries, the results of the SIALON project represent the first time in which UNGASS indicators were put into practice at the National level through a crosssectional survey. In designing the SIALON questionnaire, four indicators were taken into account, focusing on high risk population, namely MSM. UNGASS indicators have proven to be effective measures to be considered in surveillance systems and in a comprehensive national monitoring and in an evidence-based evaluation approach.

\subsubsection{UNGASS indicator $\mathrm{N}^{\circ} 8$}

In order to measure the HIV testing level, a specific UNGASS indicator was set, namely the UNGASS 8. This indicator refers to the percentage of MSM tested for HIV in the last 12 months and who know/collected the result, with the purpose of monitoring advancement in promoting HIV VCT among most-at-risk populations, in this case MSM. The indicator foresees as a numerator the number of most-at-risk population respondents who have been tested for HIV during the last 12 months and who know the results and as denominators the number of most-at-risk population included in the sample (Fig. 4).

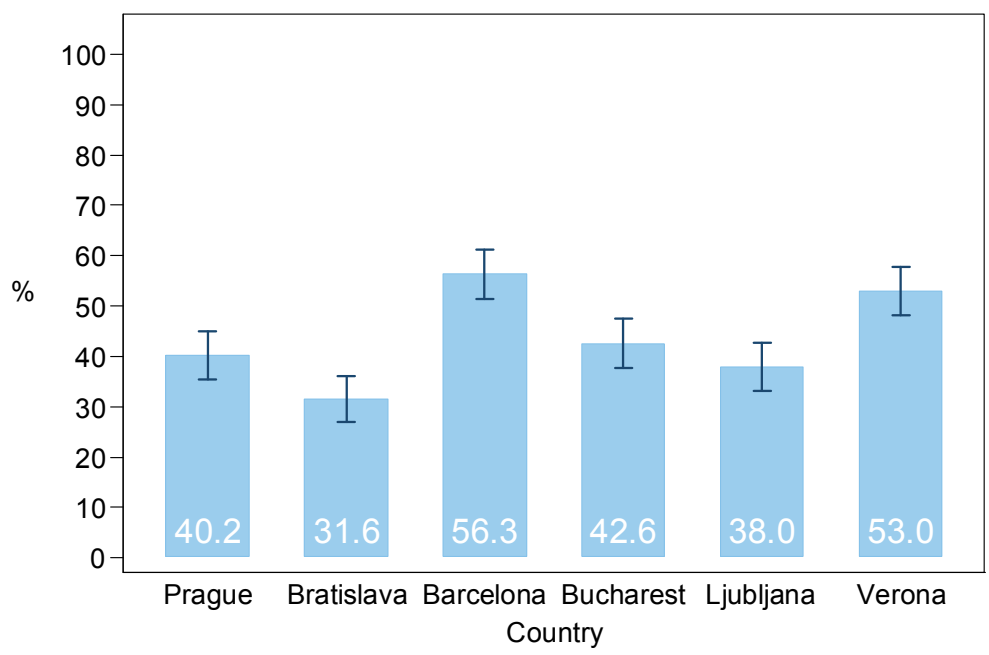

Fig. 4. UNGASS indicator N. 8: MSM who were tested in the last 12 month and knew the result

The Southern European cities had a high percentage of tested people who collected the test result (56.3\% in Barcelona and $53.0 \%$ in Verona). In the other cities, low percentages are reported: $31.6 \%$ in Bratislava, $42.6 \%$ in Bucharest, $38.0 \%$ in Ljubljana and $40.2 \%$ in Prague.

\subsubsection{UNGASS indicator $\mathrm{N}^{\circ} 9$}

This indicator refers to the percentage of most-at-risk populations reached with HIV prevention programmes. With regard to the construction of the indicator, the numerator is 
the number of respondents who replied that they have been given condoms for free in the last 12 months and knew where to go if they wished to be given an HIV test. The denominator is the number of MSM involved in the survey (Fig. 5).

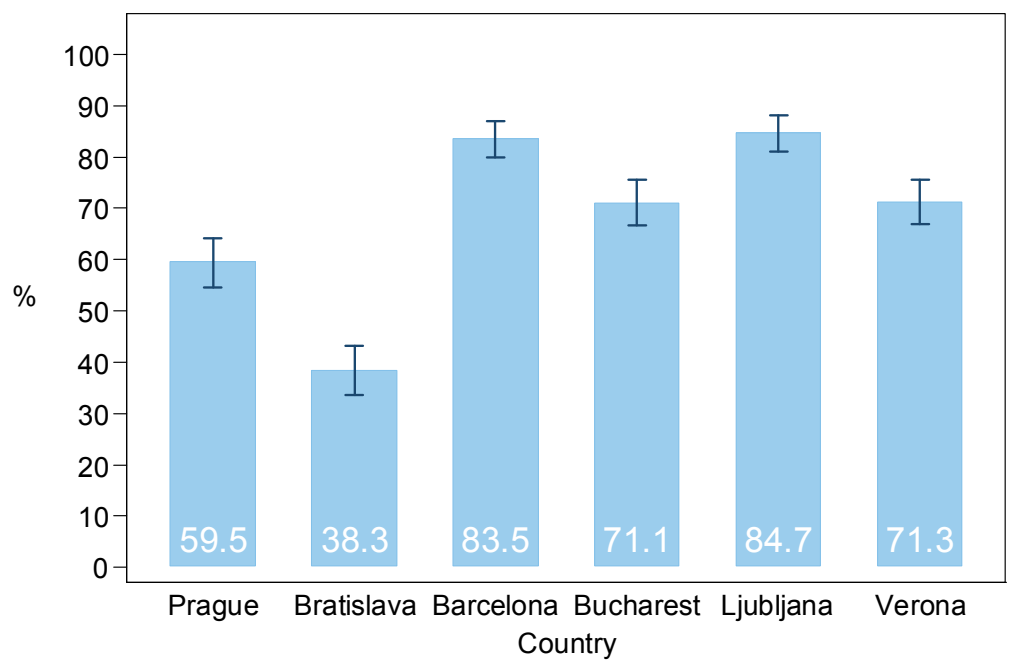

Fig. 5. UNGASS indicator N. 9: MSM reached by prevention programmes

The highest percentages of participants reached by prevention programmes are reported in Ljubljana $(84.7 \%)$ and Barcelona (83.5\%), while the lowest are in Prague $(59.5 \%)$ and Bratislava (38.3\%). In Verona, the percentage is $71.3 \%$, while in Bucharest it is $71.1 \%$. According to the UNGASS request of disaggregating the data according to the age group $(<25 / 25+)$, young people $(<25$ years old $)$ were less reached by prevention programmes than older people $(61.4 \%$ and $72.0 \%$ respectively).

\subsubsection{UNGASS indicator $\mathrm{N}^{\circ} 19$}

This indicator describes the percentage of men reporting the use of a condom during their last anal sex intercourse with a male partner. The goal is to monitor the condom use among MSM, as it represents the main means for risk reduction. In this case, the numerator is the number of respondents who reported that a condom was used the last time they had anal sex, while the denominator is the number of respondents who reported having had anal sex with a male partner in the last six months (Fig. 6).

UNGASS 19 with steady and casual partner was calculated. As shown in Fig. 6, the percentage of participants who reported the use of a condom the last time they had anal sex with a male partner in the last 6 months with their steady partner was highest in Barcelona (35.1\%) and lowest in Prague (19.1\%). The percentage with occasional partner was highest in Barcelona (64.3\%) and lowest in Bratislava (39.7\%). 


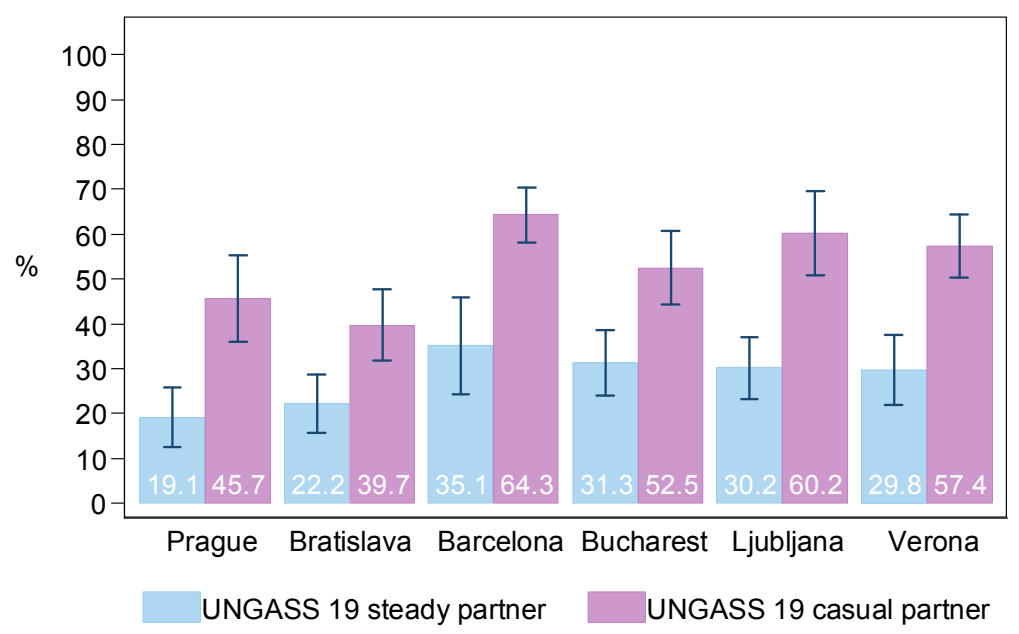

Fig. 6. UNGASS indicator N. 19: MSM reporting the use of a condom the last time they had anal sex with a male partner in the last 6 months: steady and occasional partners.

\subsubsection{UNGASS indicator $\mathrm{N}^{\circ} 23$}

The UNGASS 23 refers to the HIV prevalence in a specific population, representing therefore the main indicator. This indicator allows to directly assess improvement in containing HIV levels among most-at-risk, namely MSM. In this case, the prevalence was calculated from the oral fluid tests performed in the central laboratory (Fig. 7).

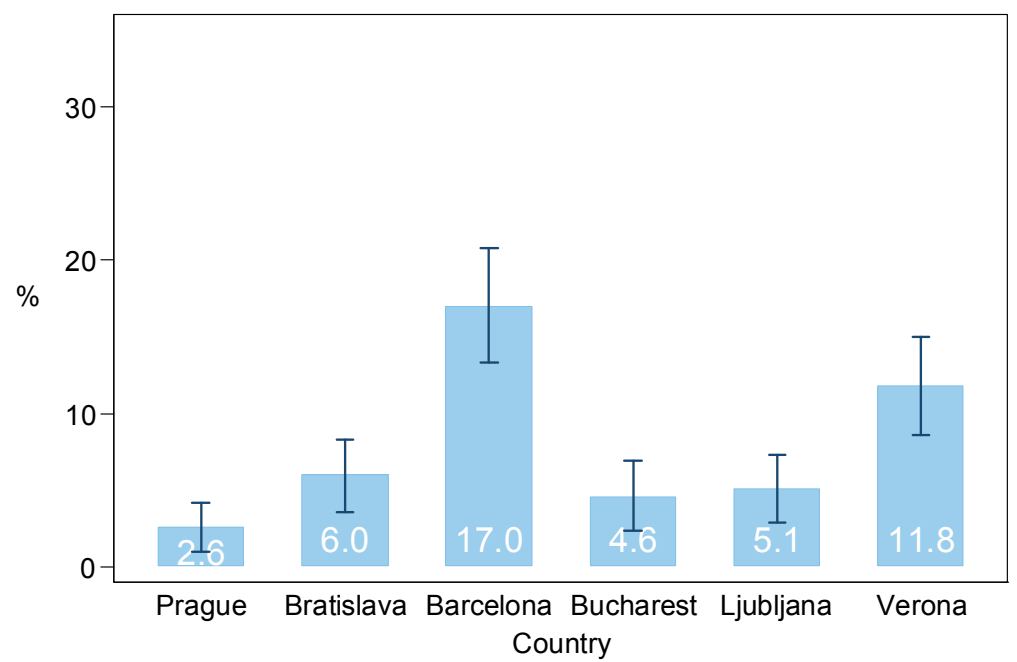

Fig. 7. UNGASS indicator N. 23 HIV prevalence 
HIV percentages are $17.0 \%$ in Barcelona and $11.8 \%$ in Verona. Lower percentages were calculated in Bratislava (6.0\%), Bucharest (4.6\%) and Ljubljana (5.1\%). In Prague, HIV level was $2.6 \%$.

\subsection{HIV prevalence}

As reported in the UNGASS 23, data regarding HIV prevalence levels were calculated through the oral fluid samples tests. As mentioned before, the cities with the highest HIV prevalence were Barcelona $(17.0 \%)$ and Verona $(11.8 \%)$. Lower percentages were reported in Bratislava $(6.0 \%)$, Bucharest $(4.6 \%)$ and Ljubljana (5.1\%). Prague had the lowest HIV prevalence $(2.6 \%)$. The overall prevalence of HIV positive oral fluid samples was $7.9 \%$. Previous studies carried out in some of the participating cities, came to quite different prevalence estimates. For instance, in Barcelona HIV prevalence found in previous studies using a convenience sample was slightly higher than the prevalence found in the SIALON study. The lower levels reported in Ljubljana and Bratislava in previous studies may be partly due to the different sampling method adopted and lower number of MSM recruited in the study.

\subsubsection{HIV prevalence by age}

The prevalence according to age group is represented in Table 3. In the overall sample, prevalence of HIV among young people (less than 25 years old) was significantly lower than among people of over 25 years of age (3.5\% vs $9.6 \%$ ). This difference in prevalence according to age group was also significant in Ljubljana where no HIV positive cases were found among younger MSM, and in Bratislava where $1.7 \%$ of younger MSM were HIV positive compared to $7.6 \%$ of older ones.

\begin{tabular}{|l|c|c|c|c|c|c|c|c|c|c|}
\hline & \multicolumn{3}{|c|}{ Negative } & \multicolumn{3}{c|}{ Positive } & \multicolumn{2}{c|}{ Total } \\
\hline Age group & No. & $\mathbf{9}$ & \multicolumn{9}{|c|}{$\mathbf{9 5 \%}$ Conf. Interval } & No. & \% & \multicolumn{9}{c|}{ 55\% Conf. Interval } & No. & $\%$ \\
\hline$<25$ & 553 & 96.5 & 95.0 & 98.0 & 20 & 3.5 & 2.0 & 5.0 & 573 & 100.0 \\
\hline$>=25$ & 1447 & 90.4 & 88.9 & 91.8 & 154 & 9.6 & 8.2 & 11.1 & 1601 & 100.0 \\
\hline Total & 2000 & 92.0 & 91.0 & 93.2 & 174 & 8.0 & 6.8 & 9.0 & 2174 & 100.0 \\
\hline
\end{tabular}

Table 3. HIV result according to age group

The mean age of HIV positive MSM was 36, significantly higher than the mean for HIV negative people (31.6 years). Table 4 shows the mean age of HIV positive people by country. This figure was lowest in Bucharest (27.1 years old) and the highest in Verona (38.9 years old).

\begin{tabular}{|l|c|c|c|}
\hline Age group & Mean & \multicolumn{2}{|c|}{ 95\% Conf. Interval } \\
\hline Prague & 32.3 & 28.2 & 36.3 \\
\hline Bratislava & 34.8 & 30.9 & 38.8 \\
\hline Barcelona & 37.5 & 35.1 & 39.8 \\
\hline Bucharest & 27.1 & 23.5 & 30.8 \\
\hline Ljubljana & 35.1 & 32.2 & 38.0 \\
\hline Verona & 38.9 & 36.3 & 41.5 \\
\hline Total & 36.0 & 34.7 & 37.4 \\
\hline
\end{tabular}

Table 4. Mean of age of HIV positive people by country 


\subsubsection{HIV prevalence by venue type}

As shown in Fig. 8, HIV prevalence, based on oral fluid samples, was higher in subjects recruited in sex-focused venues like saunas $(14.3 \%)$, cruising venues $(15.2 \%)$ sex shops and naked parties $(11.5 \%)$ than in other venues such as discos and bars $(4.6 \%$ and $6.7 \%$ respectively).

At city level, HIV prevalence by type of venue (sex focused versus non-sex focused) was significantly higher in sex focused venues in Verona, Bratislava and Ljubljana.

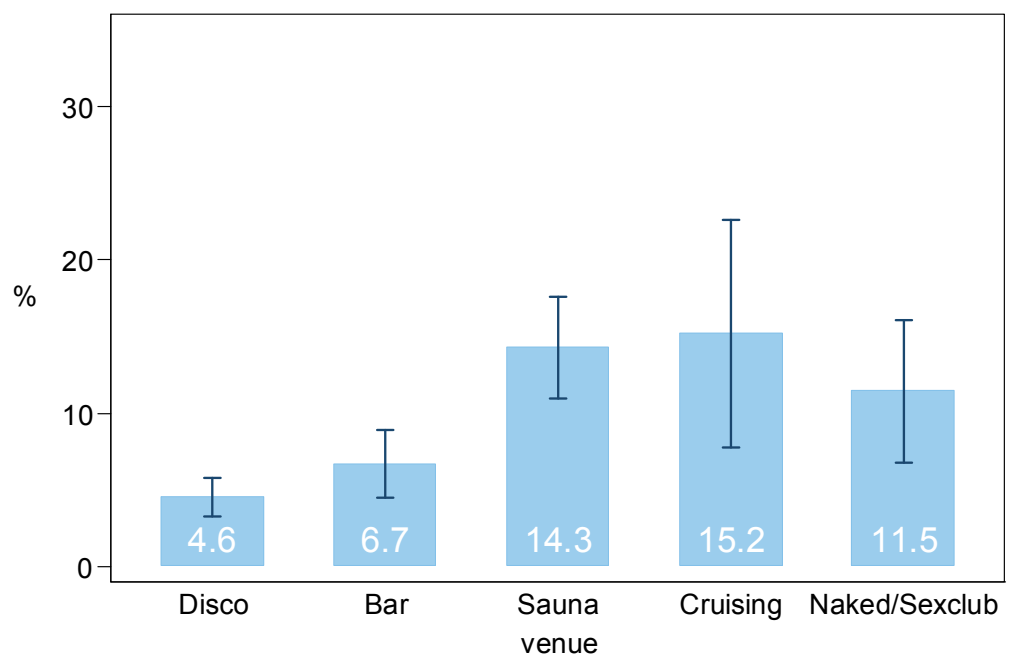

Fig. 8. HIV Prevalence by venue type

\subsubsection{Knowledge of actual HIV status and undiagnosed infection}

$56 \%$ of HIV positive people were not aware of their HIV serostatus, that is, they declared they had never been tested $(7.8 \%)$, were found to be HIV negative at their last HIV test $(47.6 \%)$ or didn't collect their result $(0.6 \%)$. As shown in Fig. 9, the rates of people unaware of their HIV positive status were almost $80 \%$ in Bucharest and Ljubljana and lower than $50 \%$ only in Barcelona.

Moreover, the average age of people unaware of their HIV positive status was $33.9 \mathrm{y} / \mathrm{o}$ lower than that of subjects that knew their seropositivity that was $37.9 \mathrm{y} / \mathrm{o}$, based on their reported last HIV test. Another important fact is that among oral fluid HIV positive subjects, nearly one third (30.9\%) reported a negative HIV test over the last 12 months. This data seems to indicate that quite a number of infections were acquired over the last 12 months. At city level this percentage was higher than $50 \%$ in Ljubljana while the lowest figure was in Bratislava (less than 20\%). All other cities had intermediate values (nearly $30 \%$ ). 


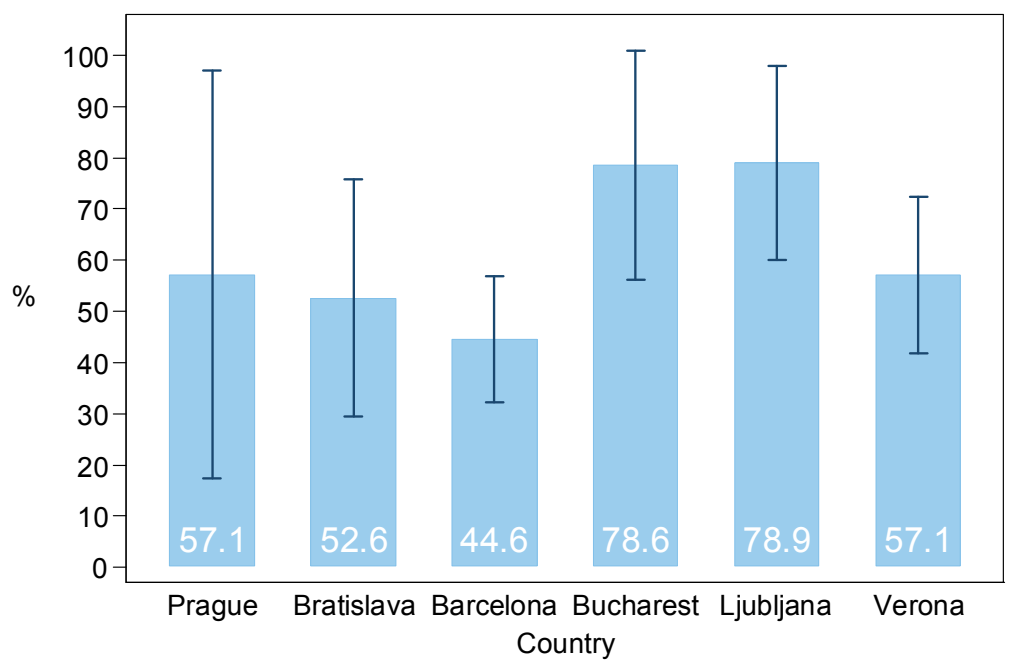

Fig. 9. Percentage of HIV positive MSM unaware of their HIV status

\subsection{Other STI infections}

\subsubsection{STI history}

Of the overall sample, $11.7 \%$ of respondents declared that they had at least one STI during the last 12 months. The highest proportion of people with a declared STI history was in Barcelona (15.3\%) and the lowest in Bucharest (6.5\%). For the details from all participating cities, see Fig. 10.

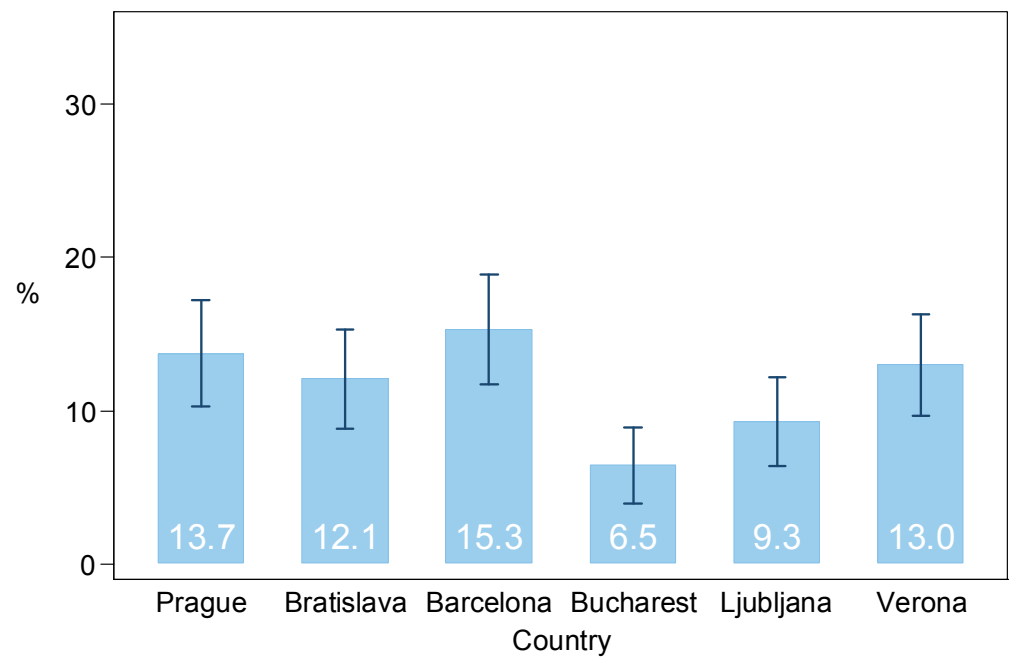

Fig. 10. STI during the last 12 months 


\subsubsection{Self reported history of Syphilis}

$2.5 \%$ of the overall sample had had Syphilis during the last year. The highest percentage was in Barcelona (5.6\%) followed by Verona and Prague (3.7\% and 3.4\% respectively) while Bratislava, Bucharest and Ljubljana had the lowest figures (less than $1 \%$ ).

\subsubsection{Other STIs}

The most frequent STI was Urethritis (6.2\% including Gonorrhoea and Chlamydia), followed by anogenital warts (2.5\%), Hepatitis B (1.2\%) and genital herpes $(1.0 \%)$. The distribution by city is shown in Fig. 11. The Urethritis category, including Gonorrhoea and Chlamydia, appears to be the most frequent in all cities. The second most frequent STI was anogenital warts in all the cities.

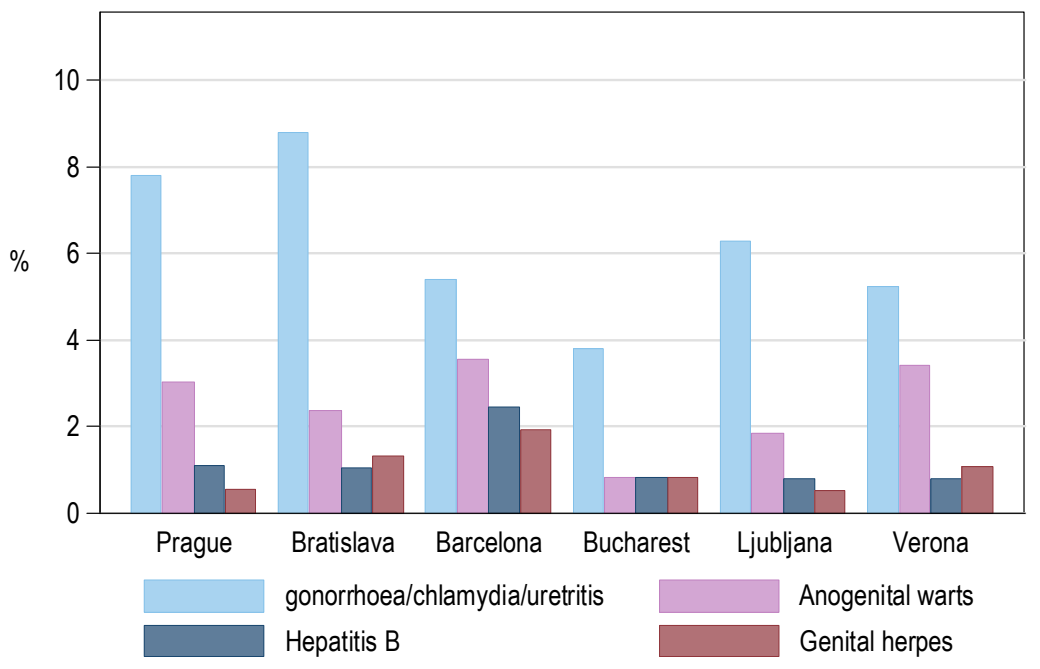

Fig. 11. Other STIs during the last 12 months by city

\subsection{Risk behaviour}

As mentioned in section 3.2.1, when designing the questionnaire, a number of questions were included to collect information on risk behaviours, which are proven to be widely adopted in the MSM community. This section provides data collected regarding the most at risk behaviours, namely unprotected anal intercourse (UAI) and the use of alcohol and drugs before or while having sex.

\subsubsection{UAI}

Unprotected anal intercourse during the last 6 months with steady and casual partners was calculated. As shown in Fig. 12, the percentage of participants who reported UAI over the last 6 months with their steady partner was highest in Prague (74.2\%) and Bratislava (72.5\%) 
and lowest in Verona (58.1\%). With regard to UAI with an occasional partner, this behaviour was reported in Bucharest in almost $60 \%$ of respondents, while in Prague the percentage reaches $46.5 \%$, in Bratislava $45.7 \%$, and similar percentages in Barcelona, Ljubljana and Verona $(33.7 \%, 32.0 \%, 33.0 \%$ in this order). The percentage of MSM reporting UAI was significantly higher among young people $(<25$ years of age, according to the UNGASS disaggregation cut-off) with a steady $(70.8 \%)$ and occasional $(51.2 \%)$ partner $(\mathrm{P}<0.05$ and $\mathrm{P}<0.001$ respectively) compared to older people $(64.9 \%$ and $37.8 \%$ in that order).

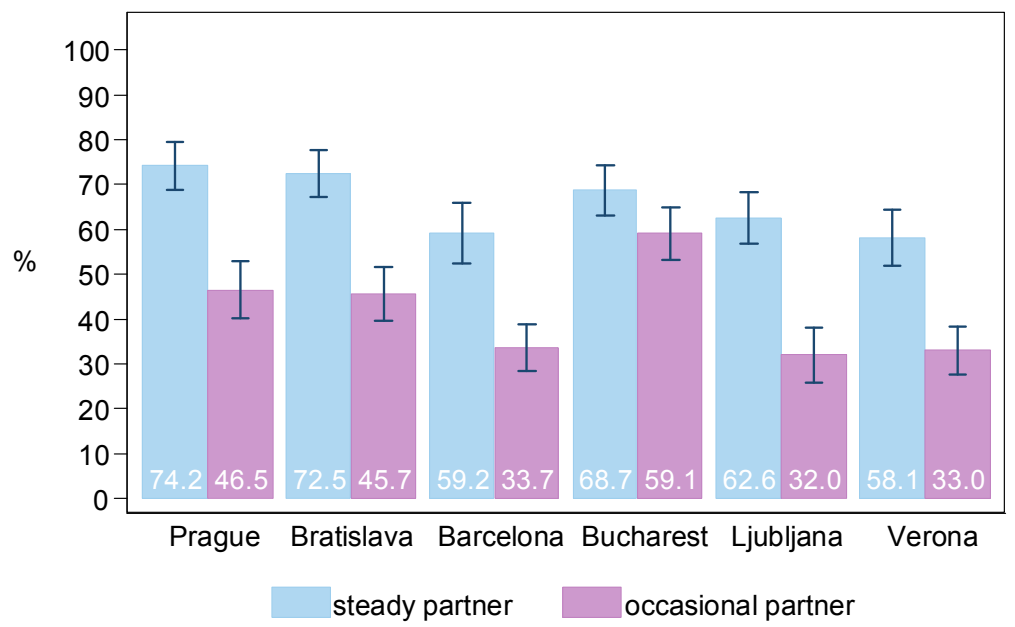

Fig. 12. UAI in the last 6 months with steady and occasional partner

\subsubsection{Alcohol and drug use}

As the alcohol and recreational drug use seems to be connected to an increase in unprotected sexual practices, the use of alcohol and drug before or during sex was included in the questionnaire.

With regard to alcohol use is concerned (Fig. 13), a significant percentage of respondents in the overall sample stated that they had used alcohol before or during sex in the last 6 months. The percentage of subjects reach $82.9 \%$ in Bratislava, $54.2 \%$ in Verona, $85.0 \%$ in Prague, $66.0 \%$ in Barcelona, $64.3 \%$ in Bucharest, while the level is of $72.3 \%$ in Ljubljana. With regards to the alcohol use before or during their last sexual encounter, percentages are lower compared with the last 6 months. The levels of alcohol use are in this case high in Prague (56.0\%), Bucharest (46.3\%), Bratislava (45.2\%), Barcelona (43.0\%), while rates lower than $40 \%$ were found only in Ljubljana and Verona (32.2\% and $23.2 \%$ respectively).

With regard to drug use (see Fig. 14), drug use before or during sex in the last 6 months seems to be widely present in the sample. In Ljubljana the percentage reaches $58.8 \%$, in Barcelona 57.1\%, in Prague 52.7\%. Low percentages are reported in Bucharest $(33.2 \%)$, Verona $(34.3 \%)$ and Bratislava (44.5\%). Here again the proportion of people using drugs during sex was significantly higher among HIV positive $(68.5 \%)$ than negative $(44.9 \%)$ people $(\mathrm{P}<0.001)$. 


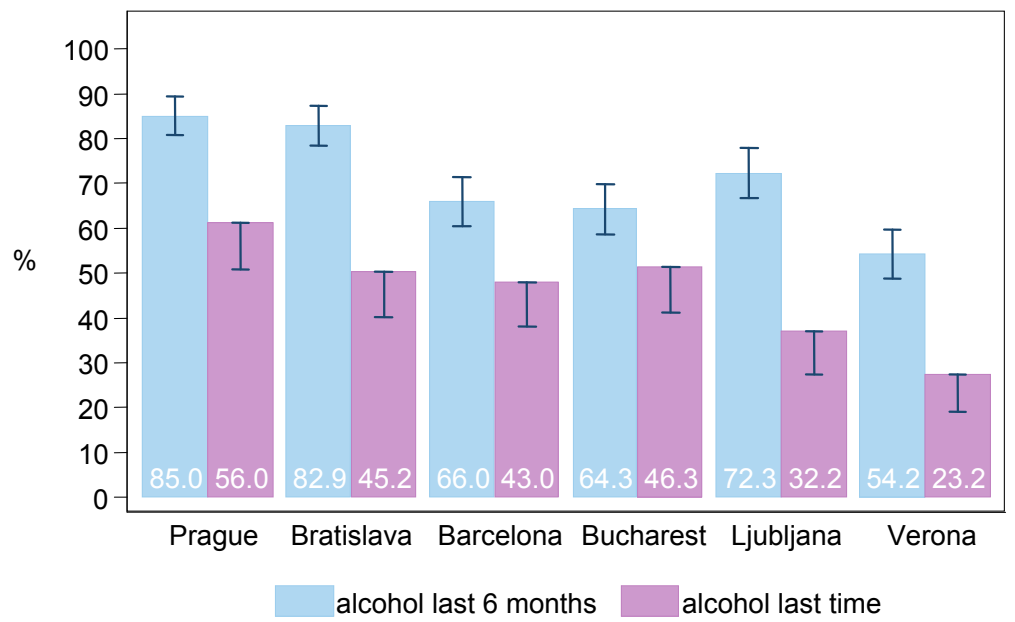

Fig. 13. Alcohol use before or while having sex in the last six months and in the last sexual intercourse

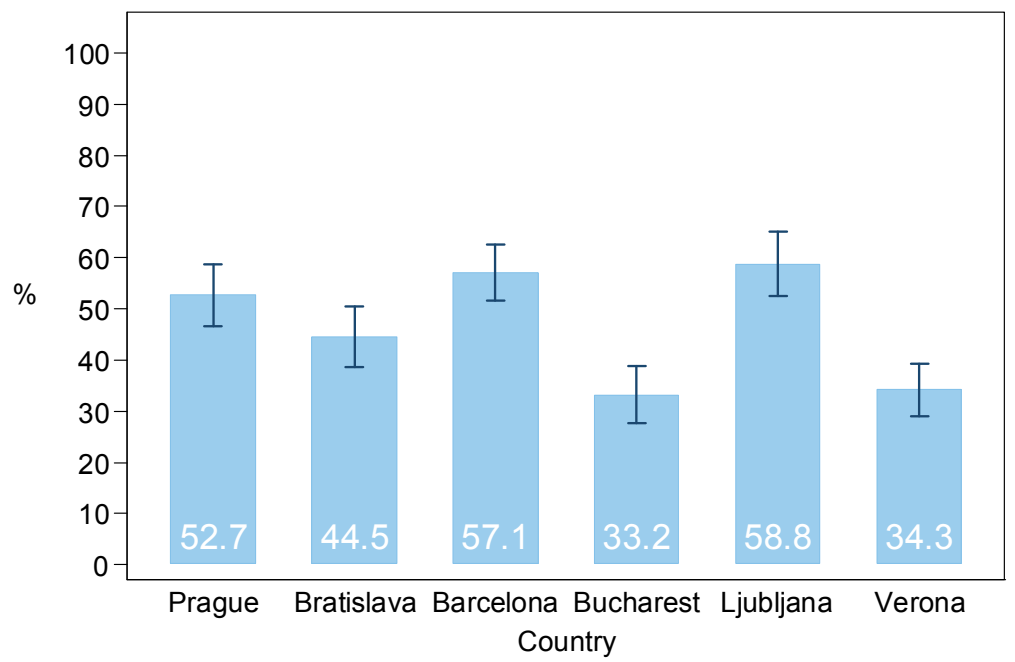

Fig. 14. Drug use before or while having sex in the last six months

\section{Conclusions}

In terms of the methodology, the use of TLS as a sampling method proved to be efficient and easily applicable especially in cities where gay scenes are highly developed and, in line 
with the scientific literature, it increases the possibility of involving a variety of participants from the target population.

In implementing this method, the formative research is a crucial step of the process. The initial identification and selection of all gay venues (bars, discos, saunas, cruising venues, sex-shops, sex-clubs, special events) is a key factor for including all possible places and events and creating a list of all possible time-space units.

Moreover, it should be pointed out that in this project different ways of recruiting MSM, such as internet, chat rooms and so on, were excluded. In actual fact, these virtual settings seem to play a very important role in the process of socialising and finding potential sexual partners among MSM. Nevertheless, the selection of "real" gay venues allowed to collect both behavioural data (questionnaire) and biological data (oral fluid sample). In this way, it was possible to triangulate behavioural data, risk factors, and HIV prevalence and to obtain reliable information on epidemic patterns.

With regard to oral fluid sample collection, this procedure has clear advantages in terms of simplifying both the data collection and the diagnostic processes in community settings, compared to venopuncture. Oral fluid testing proved to be an ideal tool for surveillance and epidemiological purposes in outreach settings among high-risk and hard to reach populations, namely MSM. The acceptability of this biological data collection procedure in gay settings is proven by the number of samples collected in all sites confirmed.

Furthermore, the SIALON project methodology included several epidemiological approaches: first of all, the Second Generation Surveillance System philosophy, which strongly suggests the combination of both behavioural and biological data and the regular replication of surveillance survey. Secondly, the implementation of UNGASS indicators, which proved to be very useful in focusing on specific topics such as access to prevention (testing and prevention programmes), high risk behaviours and HIV prevalence. Indicators related to HIV testing, prevention programs, condom use, and understanding of how to protect against HIV infection, revealed how many MSM are unaware of their HIV status and fail to practice behaviour that could protect them from infection.

This very approach seems to be a crucial activity in order to develop, pilot and validate multi-faceted epidemiological approaches in monitoring HIV epidemic.

In terms of the data collected, the highest rates of HIV seroprevalence were found in Southern European cities, namely Barcelona and Verona. This could be partly attributed to the older samples and therefore to longer exposure to risk, since HIV prevalence was higher among MSM of over 25.

The highest rates of syphilis prevalence were also found in Barcelona and Verona. In general, data confirms that a correlation exists between STI, previous syphilis, IgG antiTreponema seroprevalence and HIV infection.

Alarming findings included undiagnosed HIV infections. Over half the respondents were unaware of their HIV positive status. This proportion was slightly lower only in Barcelona, but very high (nearly 80\%) in Ljubljana and Bucharest. Moreover, nearly one third of MSM found to be HIV-positive through oral fluid samples reported a negative HIV test result over the last 12 months, so the undiagnosed infections were recent. This figure was highest in Bucharest (over 50\%) and lowest in Bratislava (less than 20\%). 
The risk of HIV infection was assessed with a major focus on unprotected anal intercourse (UAI). Two respondents out of ten reported having had UAI with an occasional partner the last time they had sex, while four out of ten reported having had UAI in the last 6 months with this kind of partner or partners. The percentages of UAI with an occasional partner were highest in Bucharest, Prague and Bratislava both for the last sexual encounter and for encounters over the previous 6 months. In line with this finding, in these cities MSM reported less use of a condom for anal intercourse the last time they had anal sex. Young MSM exhibited the riskiest behaviour, as the highest rates of UAI with occasional partners, both last time and in the last 6 months, were found amongst young people under 25 years old. As expected, UAI with a steady partner was more frequent than with an occasional partner, in the overall sample and in all the cities.

Finally, the association between HIV risk and alcohol and drug use was confirmed. At least one third of respondents had used drugs before or during sex over the last six months and half the respondents had used alcohol. This proportion was above half in Ljubljana, Barcelona and Prague for drugs, and higher than $80 \%$ in Prague and Bratislava.

This data suggests the (i) the need for health promotion and prevention messages particularly focused on sexual behaviour and alcohol and drug use (ii) the need for prevention and information programmes for STIs given that the presence of an STIs increases the risk of HIV infection (iii) the need for policies and strategies promoting VCT among hard to reach populations such as MSM, especially young MSM.

\section{Acknowledgements}

Financial support:

The Capacity building in HIV/Syphilis prevalence estimation using non-invasive methods among MSM in Southern and Eastern Europe - SIALON project was funded by the European Commission under the European Commission Public Health Programme 20032008.

The sole responsibility for this article lies with the authors and the European Commission is not responsible for any use that might be made of the information contained therein.

The SIALON Network is composed by:

Yuri Amirkhanian (CAIR - Medical College of Wisconsin, USA) Eva Baldassari (Mental Health Department, ULSS20, Verona) Luigi Bertinato (Service for International Social and Health Relations, ULSS20, Veneto Region, Verona) Chrisoula Botsi (HCDCP, Athens) Michele Breveglieri (Regional Centre for Health Promotion, Verona) Enrica Castellani (Regional Centre for Health Promotion, Verona) Paola Coato (Azienda Ospedaliera Universitaria Integrata Verona, Department of Pathology, Section of Microbiology) Jonathan Elford (City University London) Cinta Folch (CEEISCAT Badalona Barcelona) Roberta Fontana (Microbiology - Verona University Hospital) Mauro Fornasiero (University of Bristol, England, UK) Jean-Pierre Foschia (Regional Centre for Health Promotion, Verona) Martina Furegato (Regional Centre for Health Promotion, Verona) Lorenzo Gios (Azienda Ospedaliera Universitaria Integrata Verona, Verona) Jaroslav Gyurik (Association of AIDS Help, Bratislava) Victoria Gonzalez (CEEISCAT Hospital Universitari Germans Trias i PUjol, Badalona) Valentina Guarnieri (Microbiology - Azienda Ospedaliera Universitaria 
Integrata Verona) Monika Habekova (NRC HIV/AIDS Slovak Univeristy, Bratislava) Alex Horky (Czech Youth Queer Organisation) Jaroslav Jedlicka (NIPH, Prague) Kostantinos Kampourakis (Act-up Hellas, Athens) Igor Krampac (Regional Public Health Institute Maribor, Slovenia) Massimiliano Lanzafame (Azienda Ospedaliera Universitaria Integrata Verona, Infectious Diseases Unit) Emanuela Lattuada (Azienda Ospedaliera Universitaria Integrata Verona) Roberta Martini (International Health and Social Affairs, Veneto Region) Massimo Mirandola (Azienda Ospedaliera Universitaria Integrata Verona, Verona) Zeno Menegazzi (Arcigay Pianeta Urano, Verona) Silvana Menichelli (Regional Centre for Health Promotion, Verona) Gianmichele Moise (STD Centre, Gorizia) Sabrina Montante (Veneto Region) Rafael Muñoz Castro (STOP SIDA, Barcelona) Daniela Negri (Veneto Region) Georgios Nikolopoulos (HCDCP, Athens) Irina Nita (ACCEPT, Bucharest) Paolo Patanè (Arcigay, Italy) Daniela Pitigoi (Matei Bals Institute, Bucharest) Peter Porubsky (Czech Aids Help Society) Ivo Prochazka (Czech Aids Help Society, Prague) Alexandru Rafila (Matei Bals Institute, Bucharest) Dunia Ramarli (Azienda Ospedaliera Universitaria Integrata Verona, Department of Pathology, Section of Immunology) David Rivett (independent consultant specialising in Health Promotion and Education) Miran Solinc (SKUC Magnus, Ljubljana) Danica Staneková (NRC HIV/AIDS Slovak University, Bratislava) Dzamila Stehlikova (NIPH, Prague) Barbara Suligoi (ISS, Rome) Igor Toskin (Department of Reproductive Health \& Research WHO, Geneva) Lev Zohrabyan (Regional Support Team, Europe and Central Asia UNAIDS, Moscow) Elisabetta Tonolli (Azienda Ospedaliera Universitaria Integrata Verona, Department of Pathology, Section of Microbiology) Ruggero Ughetti (Regional Centre for Health Promotion, Verona) (Hana Zakoucka (NIPH, Prague) Alessandro Zan (Arcigay Veneto) Alin Robert Zoltan (ACCEPT, Bucharest)

\section{References}

Dodds, J.D.; Mercey, D.E.; Parry, J.V.; Johnson, A.M. (2004). Increasing risk behaviour and high levels of undiagnosed HIV infection in a community sample of homosexual men. Sexually Transmitted Infections, vol. 80, 2004, pp. 236-240, ISSN 1472-3263

European Centre for Disease Prevention and Control (ECDC) \& World Health Organization (WHO) - Regional Office for Europe. HIV/AIDS surveillance in Europe 2009. Stockholm: European Centre for Disease Prevention and Control, 2010

Folch, C.; Casabona, J.; Munoz, R.; Zaragoza, K. (2005). [Trends in the prevalence of HIV infection and risk behaviours in homo- and bisexual men]. Gaceta Sanitaria, vol. 19(4), 2005, pp. 294-301, ISSN 0213-9111, Spanish

Gallagher, K.M.; Finlayson, T.; Sanchez, T.; Lansky, A.; Sullivan, P.S. (2007). Surveillance of HIV risk and prevention behaviors of men who have sex with men-a national application of venue-based, time-space sampling. Public Health Reports, vol. 122 Suppl. 1, 2007, pp. 39-47, ISSN 0033-3549

Joint United Nations Programme on HIV/AIDS (UNAIDS) and World Health Organization (WHO) (2009). Monitoring the Declaration of Commitment on HIV/AIDS: guidelines on construction of core indicators: 2010 reporting. Geneva: UNAIDS 2009, available from: http://www.unaids.org

Joint United Nations Programme on HIV/AIDS (UNAIDS) and World Health Organization (WHO) (2002). Initiating second generation HIV surveillance systems: practical guidelines. UNAIDS-WHO, retrieved from: http://www.who.int/hiv/pub/surveillance/guidelines/en/index.html 
Joint United Nations Programme on HIV/AIDS (UNAIDS) and World Health Organization (WHO) (2005). The pre-surveillance assessment. Guidelines for planning serosurveillance of $H I V$, prevalence of sexually transmitted infections and behavioural components of second generation surveillance of HIV. UNAIDS-WHO, retrieved from: http://www.who.int/hiv/pub/surveillance/sti/en/index.html

Likatavičius, G.; Klavs, I.; Devaux, I.; Alix, J.; Nardone, A. (2008). An increase in newly diagnosed HIV cases reported among men who have sex with men in Europe, 2000-6: implications for a European public health strategy, Sexually Transmitted Infections, vol. 84, 2008, pp. 499-505, ISSN 1472-3263

MacKellar, D.A.; Gallagher, K.M.; Finlayson, T.; Sanchez, T.; Lansky, A.; Sullivan, P.S. (2007). Surveillance of HIV risk and prevention behaviors of men who have sex with men: a national application of venue-based, time-space sampling. Public Health Reports, vol. 122 Suppl. 1, 2007, pp.39-47, ISSN 0033-3549

MacKellar, D.A.; Valleroy, L.A.; Secura, G.M.; Behel, S.; Bingham, T.; Celentano, D.D.; Koblin, B.A.; Lalota, M.; McFarland, W.; Shehan, D.; Thiede, H.; Torian, L.V.; Janssen, R.S.; Young Men's Survey Study Group. (2005). Unrecognized HIV infection, risk behaviors, and perceptions of risk among young men who have sex with men: opportunities for advancing HIV prevention in the third decade of HIV/AIDS. Journal of Acquired Immune Deficiency Syndromes, vol. 38(5), 2005, pp. 603-14, ISSN 1525-4135

Mirandola, M.; Folch Toda, C.; Krampac, I.; Nita, I.; Stanekova, D.; Stehlikova, D.; Toskin, I.; Gios, L.; Foschia, J.P.; Breveglieri, M.; Furegato, M.; Castellani, E.; Bonavina, M.G.; the SIALON network. (2009). HIV bio-behavioural survey among men who have sex with men in Barcelona, Bratislava, Bucharest, Ljubljana, Prague and Verona, 2008-2009. Euro Surveillance, vol. 14(48), ISSN 1560-7917, retrieved from: http:// www.eurosurveillance.org/ViewArticle.aspx?ArticleId=19427

Muhib, FB.; Lin, LS.; Stueve, A.; Miller, R.L.; Ford, W.L.; Johnson, W.D. (2001). A venuebased method for sampling hard-to-reach populations. Public Health Reports, vol. 116 Suppl. 1, 2001, pp. 216-22, ISSN 0033-3549

Stueve, A. ; O'Donnell L.N.; Duran, R.; San Doval, A.; Blome, J. (2001). Time-space sampling in minority communities: results with young Latino men who have sex with men. American Journal of Public Health, vol. 91(6), 2001, pp. 922-6, ISSN 1541-0048

Van de Laar, M.J. (2009). HIV/AIDS and other STI in men who have sex with men - a continuous challenge for public health. Euro Surveillance, vol. 14(47), ISSN 15607917

Williamson, L.M. \& Hart, G.J. (2007). HIV prevalence and undiagnosed infection among a community sample of gay men in Scotland. Journal of Acquired Immune Deficiency Syndromes, vol. 45(2), 2007, pp. 224-30, ISSN 1525-4135 


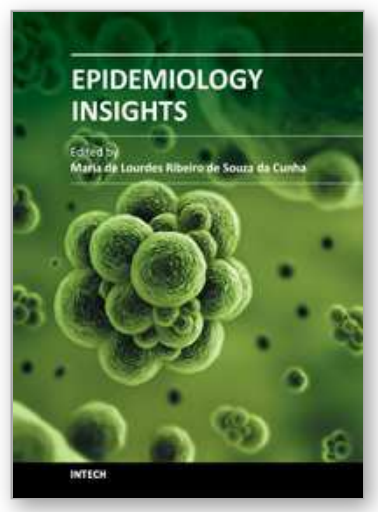

\author{
Epidemiology Insights \\ Edited by Dr. Maria De Lourdes Ribeiro De Souza Da Cunha
}

ISBN 978-953-51-0565-7

Hard cover, 396 pages

Publisher InTech

Published online 20, April, 2012

Published in print edition April, 2012

This book represents an overview on the diverse threads of epidemiological research, brings together the expertise and enthusiasm of an international panel of leading researchers to provide a state-of-the art overview of the field. Topics include the epidemiology of dermatomycoses and Candida spp. infections, the epidemiology molecular of methicillin-resistant Staphylococcus aureus (MRSA) isolated from humans and animals, the epidemiology of varied manifestations neuro-psychiatric, virology and epidemiology, epidemiology of wildlife tuberculosis, epidemiologic approaches to the study of microbial quality of milk and milk products, Cox proportional hazards model, epidemiology of lymphoid malignancy, epidemiology of primary immunodeficiency diseases and genetic epidemiology family-based. Written by experts from around the globe, this book is reading for clinicians, researchers and students, who intend to address these issues.

\title{
How to reference
}

In order to correctly reference this scholarly work, feel free to copy and paste the following:

Massimo Mirandola, Jean-Pierre Foschia, Michele Breveglieri, Martina Furegato, Enrica Castellani, Ruth Joanna Davis, Lorenzo Gios, Dunia Ramarli and Paola Coato (2012). The SIALON Project: Report on HIV Prevalence and Risk Behaviour Among MSM in Six European Cities, Epidemiology Insights, Dr. Maria De Lourdes Ribeiro De Souza Da Cunha (Ed.), ISBN: 978-953-51-0565-7, InTech, Available from:

$\mathrm{http}: / /$ www.intechopen.com/books/epidemiology-insights/the-sialon-project-report-on-hiv-prevalence-and-riskbehaviour-among-msm-in-six-european-cities

\section{INTECH}

open science | open minds

\section{InTech Europe}

University Campus STeP Ri

Slavka Krautzeka 83/A

51000 Rijeka, Croatia

Phone: +385 (51) 770447

Fax: +385 (51) 686166

www.intechopen.com

\section{InTech China}

Unit 405, Office Block, Hotel Equatorial Shanghai

No.65, Yan An Road (West), Shanghai, 200040, China

中国上海市延安西路65号上海国际贵都大饭店办公楼 405 单元

Phone: +86-21-62489820

Fax: $+86-21-62489821$ 
(C) 2012 The Author(s). Licensee IntechOpen. This is an open access article distributed under the terms of the Creative Commons Attribution 3.0 License, which permits unrestricted use, distribution, and reproduction in any medium, provided the original work is properly cited. 